\title{
ARTICLE
}

Cite this: DOI: $10.1039 / \times 0 x x 00000 x$

\section{Carbon Nanohorns as Alternative Gene Delivery Vectors}

\author{
Javier Guerra, ${ }^{a, b}$ M. Antonia Herrero ${ }^{a}$ and Ester Vázquez $*^{a}$
}

Received 00th January 2012,

Accepted 00th January 2012

DOI: $10.1039 / \times 0 \times x 00000 x$

www.rsc.org/
This work highlights the use of carbon nanohorns as gene delivery carriers. These carbon nanomaterials are promising candidates for the development of efficient and safe non-viral vectors. The advantages are their easy modification, the incorporation of different drugs onto or within their structure, their size and the absence of metallic particles in their synthesis. Key issues such as toxicity, biodistribution and various applications are reported here.

\section{Introduction}

Single-walled carbon nanohorns (SWCNHs) belong to the family of nanostructures whose basic unit is graphene, and they consist of single tubes of 2-5 nm in diameter and a length of around 40-50 nm, with conically-closed tips which are highstrained regions with an angle of $20^{\circ}$, that correspond to five pentagonal rings located at these ends. ${ }^{1-5}$ SWCNHs selfassemble in aggregates of about $100 \mathrm{~nm}^{6}$ but they can also be individualised or part of smaller aggregates. ${ }^{7-9}$ Laser ablation methods are used to synthesize SWCNHs from highly purified graphite in the absence of metal catalysts. ${ }^{10}$ This is particularly important in nanomedicine, as metal particles have been claimed to be responsible for some of the toxicity associated with inhaled carbon nanotubes (Figure 1). ${ }^{11}$
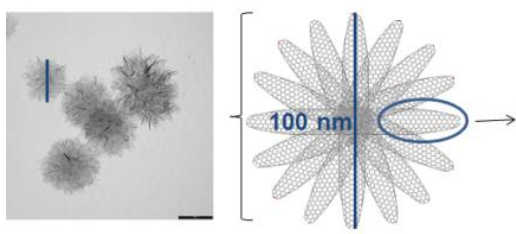

\section{0-50 nm}

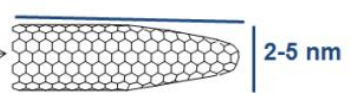

Figure 1. (Left) TEM images of the SWCNHs; (centre) graphical structure of the SWCNHs; (right) single tube of the SWCNHs.

Various features make these carbon nanomaterials promising candidates for the development of efficient and safe non-viral vectors, at least in principle. The advantages of these materials in real applications are the relatively easy modification of their surface, the incorporation of several drugs onto or within their structure, their size and the absence of metallic particles in their synthesis. These two last advantages of SWCNHs, size control and absence of metallic particles, are indeed, two of the major issues when studying the toxicity of Carbon Nanotubes.
Opposite to Single-Walled Carbon Nanotubes (SWCNTs), nanohorns do not need a previous treatment for the elimination of metal particles or for the shortening of the long fibers that can be found in SWCNTs. Based on these considerations, SWCNHs are a more promising carbon nanostructure when considering medical applications. Due to the diverse shape of SWCNHs and SWCNTs there could be also differences in the mechanism of action and cell penetration.

SWCNHs have interesting properties that make them promising platforms for the development of effective carriers: (i) high chemical stability that leads to platforms that have stable shapes and sizes; (ii) an enormous surface area in addition to an easily reached interior through holes that facilitate the encapsulation of different molecules, thus increasing the resulting payload and signifying that they can be used as nanocages; ${ }^{12-16}$

(iii) the tunable properties of the surface by means of covalent and non-covalent chemistries, even implying the simultaneous incorporation of hydrophilic and hydrophobic moieties ${ }^{17,18}$ point to materials that should have a longer lifetime for in vivo applications, thus avoiding fagocytic processes by the host immune system.

The aforementioned advantages signify that the use of SWCNHs as a drug delivery carrier has quickly expanded to different drugs such as cisplatin (cis-diaminedichloroplatinum, CDDP), ${ }^{12,14,15,19}$ doxorubicin, ${ }^{20,21}$ vancomycin hydrochloride, ${ }^{22}$ corticosteroids like prednisolone, ${ }^{23}$ or glucocorticoids such as dexamethasone. ${ }^{16}$ It is also worth mentioning the use of SWCNHs in bone regeneration in ratcalvarial bone defect with the involvement of macrophages, ${ }^{24}$ and in tissue engineering techniques such as tissue replacement. ${ }^{25}$

However, to the best of our knowledge, these materials have not previously been used as gene delivery carriers. This is surprising, as carbon nanotubes are common carriers in gene therapy and there are already many excellent papers for SWCNT based gene delivery systems. ${ }^{26-35}$ In this article, a description of our work using carbon nanohorns to construct nanocarriers for gene therapy is provided. New developments and key features 
that need to be well-defined for these materials to become a certainty in the nanomedicine market are also emphasized.

\section{Designing a gene delivery carrier}

The core challenge in gene therapy is the delivery of the genetic material (DNA, RNA, small interfering RNAs, microRNAs) to within the target cells. ${ }^{36}$ This task has been tackled with the development of two main strategies, (i) viral vectors that have the highest delivery efficiency but are expensive to produce and also undergo host immune response $;^{37,38}$ (ii) non-viral vectors that should share features that are common to other drugs, such as easy scale-up production, long-term stability and no safety risks. However, non-viral vectors have a lower gene transfer rate than viral vectors and this low efficiency is the most important weakness for these materials. ${ }^{39}$ Some very useful reviews have been published that cover the progress in this field. ${ }^{36,40-42}$

The rational design of the structure of non-viral vectors requires an awareness of the numerous frontiers that our ensemble of genetic material and the non-viral delivery agent (polyplex) will go through. ${ }^{43}$ The influence of these barriers eventually implies that there is no relationship between the in vitro and the in vivo studies. The high ionic strength that exists in a living organism engenders aggregation processes, which generate a humoral response in the host immune system. The complexity intrinsic to the journey through the different organs and tissues, and platelet aggregation are just some of the cornerstones that common nonviral vectors often do not surmount. The aforementioned barriers require a high stability of the polyplex in the living organism, until the final delivery of the genetic material, and suitably functionalised SWCNHs are therefore good candidates.

The ideal vector will have to efficiently couple the genetic material, and to traverse the extracellular environment, it must interact with the anionic cellular membranes to endocytose within the cell and to exocytose before the late endosome fuses with lysosomes. Finally, in the case of DNA, it must reach the nucleus through the nuclear envelope. ${ }^{44,45}$ It should also contain a probe that could facilitate the study of its biodistribution and location, in addition to a targeting ligand that will implement a specific targeted-therapy.

\section{SWCNHs as gene delivery carriers}

Bearing in mind the aforementioned advantages of SWCNHs, and in order to propose new non-viral vectors, we have designed an amalgamation of two components, PAMAM dendrimers and carbon nanohorns, for the construction of a new hybrid material that efficiently couples siRNA and that successfully delivers its genetic cargo within the cytoplasm, leading to the knock-down in the synthesis of different proteins. ${ }^{46,47}$ These new systems have the main advantages of the two nanocomponents: a) PAMAM dendrimers allow the electrostatic interaction of genetic material and increase the solubility of the SWCNHs; b) SWCNHs are ideal platforms on which to anchor dendrimers since the binding of these components leads to a new ensemble that is capable of performing the delivery of genetic material while simultaneously decreasing the toxicity of the PAMAM dendrimers. Moreover, the SWCNH structure permits further modifications for a more rational design of transfection reagents with which to improve their efficiency in different cell types.

Pristine SWCNHs display strong van der Waals interactions that result in poorly soluble materials. Our approach, which consists of the covalent functionalization of their structure, is a fundamental strategy for the applications of carbon nanomaterial in biological studies, thus enhancing solubility in aqueous media and providing a means to introduce new molecules with interesting properties. Scheme 1 describes the synthetic methodology for the preparation of PAMAM-SWCNH derivatives. The linker was introduced by means of a radical addition of aniline derivatives under microwave conditions ${ }^{48}$ that lead to the formation of carbon-carbon bonds. The alkylic amine groups permit further derivatization via Michael addition with methyl acrylate and ulterior coupling with the dendrimers through an amidation reaction.

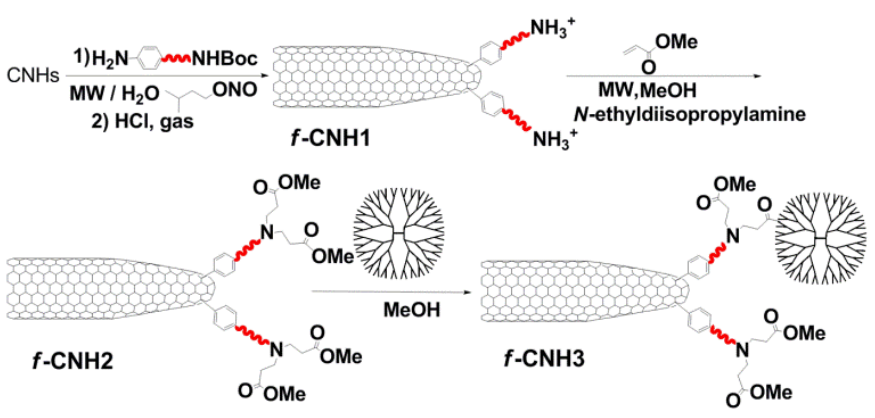

Scheme 1. Synthesis of the dendrimer-functionalised carbon nanohorn.

PAMAM dendrimer can incorporate gold nanoparticles in their cavities $^{49,50}$ and these nanoparticles can be used as markers to fully ascertain the location of the PAMAM macromolecules on the surface of the carbon nanomaterial. The presence of the gold nanoparticles with a high Z-contrast enables the use of high resolution transmission electron microscopy (HR-TEM) for the indirect visualization of the dendrimers (Figure 2).

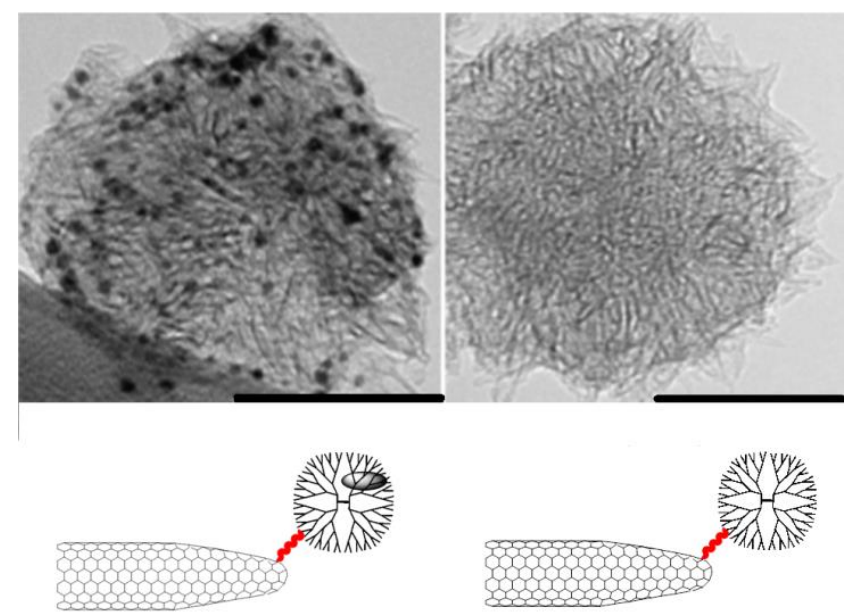

Figure 2. TEM images of the dendrimer encapsulated nanoparticles functionalised SWCNHs (left) and dendrimerfunctionalised SWCNHs without nanoparticles (right). Scale bar corresponds to $50 \mathrm{~nm}$.

High surface charge density, which is inherent to its cationic polyamine surface, has previously been addressed as a cause of the high toxicity of PAMAM dendrimers. ${ }^{51}$ In the new PAMAMSWCNH vector, the huge carbon surface exposed by SWCNHs leads to a dispersion of the positive charges, thus decreasing the surface charge density parameter. This binding also inhibits dendrimer aggregation, which may protect the system from immunogenic responses. ${ }^{52}$ In fact, when the toxicity of the system was checked, these new hybrid materials developed a less 
toxic effect than the unaltered PAMAM dendrimers. These observations are consequence of different experimental data based on lactate deshidrogenase (LDH) and 3-(4,5dimethylthiazol-2-yl)-2,5-phenyltetrazolium bromide (MTT) assays. Possible alterations of the cell membrane were also studied with propidium iodide. ${ }^{46}$

Its lack of toxicity having been initially evaluated, the PAMAMSWCNH vector was then electrostatically bound to siRNA in order to specifically knock-down the mRNA expression of different proteins such as p42-MAPK and GADPH in prostate cancer cells (PC-3). ${ }^{46}$ The protonated amino groups located at the periphery of the PAMAM dendrimers at slightly acid $\mathrm{pH}$ permit the formation of dendriplex through electrostatic interaction with the phosphate groups of the nucleic acid. Zetapotential measurements and gel electrophoresis were performed in order to evaluate the surface charges and the electrostatic interaction. These and other studies allow us to conclude that the system is able to bind siRNA and release it in the presence of heparin (a polyanion treatment that resembles the cell cytosol). The complex was able to diminish the mRNA levels of the aforementioned proteins, which in the case of p42-MAPK is directly involved in the development of cancer.

This proof-of-concept work was followed by a real case scenario in which the diminishment in a specific protein was taken as an asset to fight prostate cancer. ${ }^{47}$ Once we had demonstrated that SWCNHs can be used as non-viral carriers to deliver siRNA, ${ }^{46}$ the new vector was studied in order to efficiently silence the key proteins involved in the proliferation of prostate cancer cells and to see the effect of this silencing on the toxic actions of the antitumoural drug docetaxel. In our case, cofilin-1, a key protein in the regulation of cellular cytoskeleton, was chosen as a target. ${ }^{47}$ The SWCNH derivative was again able to bind siRNA and release it in the presence of an excess of the polyanion heparin, suggesting that the binding is reversible. Moreover, the binding to the SWCNH derivative protects the siRNA from degradation by RNAases. The protection that the SWCNH system confers to the siRNA may have its root on the steric hindrance that the horns may present against RNAases enzymes inhibiting their action as they cannot reach the key sites to chop the siRNA molecules. The complex was able to enter more than $75 \%$ of the cells present in the culture and to deliver its siRNA cargo to the cells, thus causing a decrease in both mRNA and protein levels for cofilin-1 and indicating its efficiency as a siRNA delivery agent.

It is important to note that the effect of the combination of silencing cofilin-1 and the antitumoural performance of docetaxel is not synergistic since the maximum effect produced by docetaxel is not enhanced. In other words, this means that we are not currently able to induce a higher degree of toxicity for docetaxel, although silencing cofilin-1 makes it possible to attain these therapeutic values with smaller doses. These results suggest new therapeutic approaches with which to treat tumours, potentiating the cytotoxic action of the anticancer drug by knocking down certain proteins involved in cancer cell survival and/or proliferation.

\section{Challenges and Future Perspective}

The use of genetic materials in different therapies is often limited not only by problems related to the different cellular frontiers that these materials must traverse but also by problems with administration such as lack of solubility or dispersability, inefficient biodistribution, and lack of selectivity. In this section, we address current works that solve some of these issues and we indicate future advances in the field.
Toxicity.

The detractions of the use of carbon nanomaterials for biological applications have their root in the toxicity displayed by some of them. ${ }^{11,53-61}$ However, there are several reports that indicate that SWCNHs have a minimal toxicity. ${ }^{6,10,16,53,62-67}$ Comprehensive studies show that SWCNHs are a non-irritant, non-dermal sensitizer and non-carcinogenic. ${ }^{10}$

The toxicity of carbon nanomaterials clearly depends on different factors such as: size, dispersability, functionalization, surface area, charge density and the concentration used in the biological experiments. In terms of bioaccumulation, it is worth mentioning that carbon nanomaterials are not fully inert materials and also degrade in biological media. This issue is subject to recent studies ${ }^{68-70}$ as a hot topic that deserves further attention.

While the toxicological effects of carbon nanotubes are still controversial, ${ }^{11,53-60}$ size has been defined as a key factor since it has been demonstrated that highly-purified SWCNTs and ultrashort SWCNTs were well-tolerated by Swiss mice. ${ }^{71}$ In terms of toxicity, size actually matters and has been defined as a key factor for biological applications. While pristine carbon nanotubes need an oxidation treatment to remove the traces of metallic catalysts employed in the fabrication process and to afford shortened tubes with, in general, heterogeneous sizes, this treatment is not necessary for carbon nanohorns. Hence, sizes of around $100 \mathrm{~nm}$ are adequate for enhanced permeability and retention (EPR) effect in solid tumours. This is the rationale behind the high antitumoural activity shown by oxidised SWCNHs with PEG and doxorubicin. ${ }^{20,21}$ The size of this SWCNH-PEG-doxorubicin adduct $(174 \mathrm{~nm})$ is considered to be accurate (between 120-200 nm) in order to avoid its being metabolized by the liver or spleen. These results are also supported by various works in which cisplatin is delivered with very promising in vitro and in vivo results. ${ }^{12,14,15,19}$ But the size of as-synthesised SWCNHs can also be modified in order to better control their toxicity and/or applicability. Recent important advances have taken place in the individualisation of SWCNHs. ${ }^{7-9}$ SWCNHs ultrasonically treated with surfactant have resulted in the dispersion of SWCNH aggregates. ${ }^{8}$ The biological behaviour shown by well-individualised and small SWCNHs (S-SWCNHs) is remarkable. ${ }^{66}$ These tubes are surprisingly highly hydrophilic and do not undergo uptake by different cells such as macrophages (RAW 264.7 cells), tumour cells (HeLa or KB), or normal cells (FHs 173We). More importantly, when a targeted vector is introduced onto the surface of SWCNHs (tumour-targeting folic acid (FA)), it is possible to observe a positive discrimination via receptormediated endocytosis. This high specificity is one of the main accomplishments sought for any drug carrier.

Another key aspect in carbon nanostructure toxicity is that of functionalization. It has recently been proved that appropriate chemical functionalization that leads to the debundling of carbon nanotubes (CNTs) can make them safer to use. ${ }^{72}$ In this respect, SWCNHs are more dispersible in water media and the incorporation of different organic fragments onto their surface leads to an increase in their solubility. Features such as the surface charge or the grafting density of functional groups will determine properties such as solubility, dispersability and individualisation of the carbon materials, thus making SWCNHs compatible with biological fluids. The covalent ${ }^{3,4,73-76}$ and noncovalent ${ }^{17,18,72,77}$ chemical functionalizations of SWCNHs were achieved, resulting in an increase in the solubility of the SWCNH aggregates. Covalent methodologies such as the 1,3-dipolar cycloaddition of azomethine ylides, ${ }^{4,48,78-83}$ in situ generated aryl 
diazonium salts, ${ }^{48,81,83,84}$ Bingel cyclopropanation, ${ }^{85}$ and nitrene cycloaddition, ${ }^{86}$ were applied in order to functionalise SWCNHs. Non-covalent functionalization has also proved to be very useful to increase both the dispersability and the biocompatibility of the SWCNH conjugates even in vivo experiments. ${ }^{87}$

\section{Biodistribution.}

The chemical functionalization of SWCNHs has also been determined as an important feature in terms biodistribution, since it minimises unwanted tissue accumulation. Hydrophobic and hydrophilic oxidised SWCNHs, which have also been functionalised with bovine serum albumin (BSA), have been administered intravenously. ${ }^{65}$ An important accumulation in the lungs, liver and spleen has been observed, and reduced accumulation was located at the heart, kidneys and brain. Highly hydrophobic oxSWCNHs were found in the lungs, while more hydrophilic SWCNHs were observed evenly in the lungs, liver and spleen. Those with attached BSA were taken up by the macrophage system, and accumulated in the lungs. It is worth noting that no immunological lesions were histologically reported in this study. The biodistribution was also studied using $\mathrm{Gd}_{2} \mathrm{O}_{3}$ particles that were embedded in the SWCNH dahlia structure. ${ }^{[88]}$ The presence of gadollinium facilitated the detection of the SWCNHs in fagolysosomes principally in the liver after intravenous injection. Magnetite particles $(6 \mathrm{~nm}$ in diameter) were formed in situ in hole-opened SWCNHs. ${ }^{88}$ The attached magnetite nanoparticles led to the possibility of using magnetic resonance imaging, which allowed the in vivo visualization of the accumulation of SWCNHs in the spleen and kidneys, also lacking toxicity. All these studies are very important; due to the diverse shape of carbon nanostructures, there could be also differences in the biodistribution.

\section{Hyperthermia and combined therapies.}

SWCNHs make it possible to use both their intrinsic hyperthermal properties and their properties as carriers. The amalgamation of two therapeutic treatments in a unique entity is expected to lead to considerable progress in various therapies, it being the basis for the development of a cost-effective drug. Like CNTs, SWCNHs also display hyperthermia properties owing to their absorbance in the near-infrared region and the subsequent increase in temperature as a result of this absorption of energy. ${ }^{89,90}$ Various groups have taken advantage of this effect and have used these carbon materials for photothermal tumour ablation, ${ }^{91}$ the enhanced destruction of microbes and viruses with NIR laser irradiation. ${ }^{89,92}$ Iijima and co-workers reported an optical biotechnological method using SWCNHs that transforms energy from laser light to heat in order to control heat shock promoter-mediated gene expression. ${ }^{93}$ Still the responses of SWCNHs to electromagnetic radiations should be better studied.

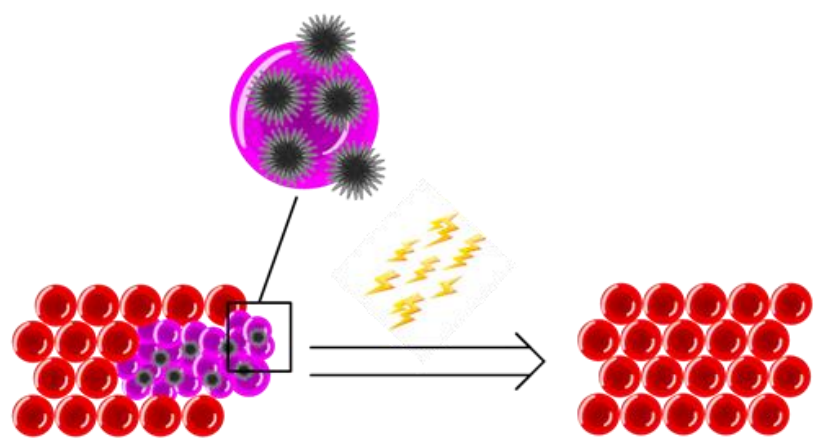

Figure 3. Ideal performance of SWCNHs selectively introduced in cancerous cells (purple). NIR irradiation leads to an increase in the temperature that causes tumor ablation.

A smart strategy has also arisen as an alternative to the introduction of functional groups on the SWCNH surface. This consists of the encapsulation of SWCNHs within a more biocompatible structure, such as liposomes. ${ }^{[87]}$ This opens up new possibilities as regards enhancing the loading capacity and a better controlled release rate. Moreover, the attachment of different targeting ligands to liposome could transport the complex structure through receptor mediated endocytosis. This is crucial when large molecules are to be released into the cytoplasm. The SWCNH core benefits the system as it serves as carriers of the hydrophobic drugs as well as it is the backbone of the nanoparticle conferring stability to the ensemble. It has recently been reported a doubled controlled drug release mechanism by this system. ${ }^{94}$

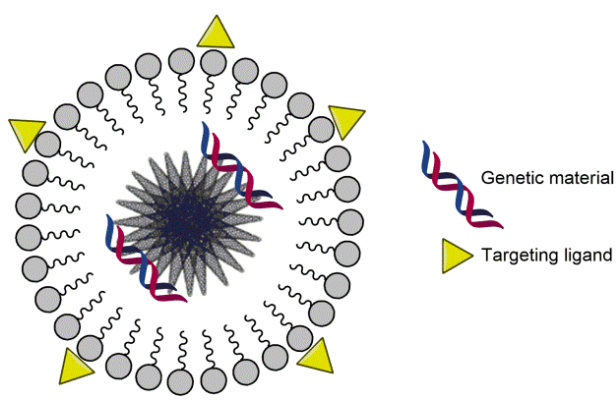

Figure 4. SWCNH dahlia bearing genetic material encapsulated in a liposome that is decorated with targeting ligands to increase the selectivity of the treatment.

\section{Conclusions}

The knowledge acquired during the last decade as regards the purification, functionalization, individualisation and enhancement of the dispersability of SWCNHs, along with their availability, have enabled their use as gene carriers. Their lack of toxicity combined with an adequate functionalization to avoid agglomeration, their high surface area, the possibility of the introduction of molecules within the cavities of oxSWCNHs, the absence of metallic particles, their regular size and their inertness are some of the features that make SWCNHs such an attractive material for the aforementioned purposes. However, there is still room for improvement. The recent works performed on the individualisation of SWCNH aggregates have resulted in new entities that merit a deeper understanding of their full potential as delivery systems. The amalgamation of different non-viral agents in a single system provides great advantages, as is the case of dendrimers on SWCNHs or SWCNHs encapsulated within liposomes. Finally, it is important to mention that the intrinsic properties of SWCNHs offer tremendous potential for the development of combined therapies, (i.e., hyperthermia). Multidisciplinary collaborations will facilitate exhaustive biological studies and highly reproducible synthetic procedures with a well-controlled polydispersity and with a comprehensive characterisation of the nanomaterials.

\section{Acknowledgements}


Authors wish to acknowledge all researchers whose work is described in this review and specially Prof. Valentín Ceña and his group for fruitful collaboration. This work has been supported, in part, by the the Spanish Ministerio de Economía y Competitividad (project CTQ2011-22410 and project BFU201130161-C02-02).

\section{Notes and references}

${ }^{a}$ Departamento de Química Inorgánica, Orgánica y Bioquímica. Facultad de Ciencias y Tecnologías Químicas. Universidad de Castilla-La Mancha. Ciudad Real, Spain. Fax: +34 926295318; Tel: +34 926295300 Ext. 3513; E-mail: Ester.vazquez@uclm.es

${ }^{b}$ Current address: R\&D Department, Crystal Pharma, Gadea Grupo Farmacéutico. Valladolid, Spain. Fax: + 34 983548113; Tel: +34 983548072.

Reference List

1 S. Iijima, M. Yudasaka, R. Yamada, S. Bandow, K. Suenaga, F. Kokai and K. Takahashi, Chem. Phys. Lett. 1999, 309, 165.

2 T. Azami, D. Kasuya, R. Yuge, M. Yudasaka, S. Iijima, T. Yoshitake and Y. Kubo, J. Phys. Chem. C 2008, 112, 1330.

3 S. Zhu and G. Xu, Nanoscale 2010, 2, 2538.

4 G. Pagona, G. Mountrichas, G. Rotas, N. Karousis, S. Pispas and N. Tagmatarchis, Int. J. Nanotechnol. 2009, 6, 176.

5 M. Yudasaka, S. Iijima and V. H. Crespi, Top. Appl. Phys. 2008, $111,605$.

6 M. Horie, L. K. Komaba, H. Fukui, H. Kato, S. Endoh, A. Nakamura, A. Miyauchi, J. Maru, E. Miyako, K. Fujita, Y. Hagihara, Y. Yoshida and H. Iwahashi, Carbon 2013, 54, 155.

7 X. Fan, J. Tan, G. Zhang and F. Zhang, Nanotechnology 2007, 18, 195103.

8 M. Zhang, M. Yudasaka, J. Miyawaki, J. Fan and S. Iijima, J. Phys. Chem. B 2005, 109, 22201.

9 M. Zhang, T. Yamaguchi, S. Iijima and M. Yudasaka, J. Phys. Chem. C 2009, 113, 11184.

10 J. Miyawaki, M. Yudasaka, T. Azami, Y. Kubo and S. Iijima, ACS Nano 2008, 2, 213.

11 A. Shvedova, V. Castranova, E. Kisin, D. Schwegler-Berry, A. Murray, V. Gandelsman, A. Maynard and P. Baron, J. Toxicol. Env. Heal. A 2003, 66, 1909.
12 K. Ajima, T. Murakami, Y. Mizoguchi, K. Tsuchida, T. Ichihashi, S. Iijima and M. Yudasaka, ACS Nano 2008, 2, 2057.

13 K. Ajima, M. Yudasaka, T. Murakami, A. Maigné, K. Shiba and S. Iijima, Mol Pharm 2005, 2, 475.

14 K. Ajima, M. Yudasaka, A. Maigné, J. Miyawaki and S. Iijima, J. Phys. Chem. B 2006, 110, 5773.

15 K. Ajima, A. Maigné, M. Yudasaka and S. Iijima, J. Phys. Chem. B 2006, 110, 19097.

16 T. Murakami, K. Ajima, J. Miyawaki, M. Yudasaka, S. Iijima and K. Shiba, Mol. Pharm. 2004, 1, 399.

17 M. Yang, M. Wada, M. Zhang, K. Kostarelos, R. Yuge, S. Iijima, M. Masuda and M. Yudasaka, Acta Biomater. 2013, 9, 4744.

18 J. Xu, S. Iijima and M. Yudasaka, Appl. Phys. A 2010, 99, 15.

19 S. Matsumura, K. Ajima, M. Yudasaka, S. Iijima and K. Shiba, Mol. Pharm. 2007, 4, 723.

20 T. Murakami, H. Sawada, G. Tamura, M. Yudasaka, S. Iijima and K. Tsuchida, Nanomedicine 2008, 3, 453.

21 T. Murakami, J. Fan, M. Yudasaka, S. Iijima and K. Shiba, Mol. Pharm. 2006, 3, 407.

22 J. Xu, M. Yudasaka, S. Kouraba, M. Sekido, Y. Yamamoto and S. Iijima, Chem. Phys. Lett. 2008, 461, 189.

23 M. Nakamura, Y. Tahara, Y. Ikehara, T. Murakami, K. Tsuchida, S. Iijima, I. Waga, M. Yudasaka, Nanotechnology 2011, 22, 465102 .

24 T. Kasai, S. Matsumura, T. Iizuka, K. Shiba, T. Kanamori, M. Yudasaka, S. Iijima and A. Yokoyama, Nanotechnology 2011, 22, 065102.

25 R. D. K. Misra, D. Depan and J. S. Shah, Acta Biomater. 2012, 8, 1908.

26 K. T. Al-Jamal, L. Gherardini, G. Bardi, A. Nunes, C. Guo, C. Bussy, M. A. Herrero, A. Bianco, M. Prato, K. Kostarelos, T. Pizzorusso, Proc. Natl. Acad. Sci. 2011, 108, 10952.

27 K. T. Al-Jamal, F. M. Toma, A. Yilmazer, H. Ali-Boucetta, A. Nunes, M. A. Herrero, B. Tian, A. Eddaoudi, W. T. Al-Jamal, A. Bianco, M. Prato, K. Kostarelos, FASEB J. 2010, 24, 4354.

28 J. E. Podesta, K. T. Al-Jamal, M. A. Herrero, B. Tian, H. AliBoucetta, V. Hegde, A. Bianco, M. Prato and K. Kostarelos, Small 2009, 5, 1176. 
29 N. W. S. Kam, Z. Liu, H. Dai, J. Am. Chem. Soc. 2005, 127, 12492.

30 Z. Liu, M. Winters, M. Holodniy and H. Dai, Angew. Chem. Int. Ed. 2007, 46, 2023

31 C. Fabbro, H. Ali-Boucetta, T. D. Ros, K. Kostarelos, A. Bianco and M. Prato, Chem. Commun. 2012, 48, 3911.

32 E. N. J. Dolatabadi, Y. Omidi, D. Curr. Nanosci. 2011, 7, 297.

33 M. Prato, K. Kostarelos and A. Bianco, Acc. Chem. Res. 2007, 41, 60.

34 S. Vardharajula, Sk. Z. Ali, P. M. Tiwari, E. Eroglu, K. Vig, V. A.. Dennis and S. R. Singh, Int. J. Nanotechnol. 2012, 7, 5361.

35 K. Yang, W. Qin, H. Tang, L. Tan, Q. Xie, M. Ma, Y. Zhang and S. Yao, J. Biomed. Mater. Res. A 2011, 99A, 231.

36 I. Posadas, J. Guerra and V. Ceña, Nanomedicine-UK 2010, 5, 1219.

37 E. Check, Nature 2005, 433, 561.

38 T. Hollon, Nat. Med. 2000, 6, 6.

39 F. Ledley, Hum. Gene Ther. 1995, 6, 1129.

40 M. A. Mintzer and E. E. Simanek, Chem. Rev. 2008, 109, 259.

41 X. Guo and L. Huang, Acc. Chem. Res. 2011, 45, 971.

42 J. P. Behr, Acc. Chem. Res. 2012, 45, 980.

43 F. C. Pérez-Martínez, I. Posadas, J. Guerra and V. Ceña, Pharm. Res. 2011, 28, 1843.

44 G. A. Pietersz, C. K. Tang and V. Apostolopoulos, Mini-Rev. Med. Chem. 2006, 6, 1285

45 D. J. Glover, D. L. Leyton, G. W. Moseley and D. A. Jans, J. Gene Med. 2010, 12, 77.

46 J. Guerra, M. A. Herrero, B. Carrión, F. C. Pérez-Martínez, M. Lucío, N. Rubio, M. Meneghetti, M. Prato, V. Ceña and E. Vázquez, Carbon 2012, 50, 2832.

47 F. C. Pérez-Martínez, B. Carrión, M. I. Lucío, N. Rubio, M. A. Herrero, E. Vázquez and V. Ceña, Biomaterials 2012, 33, 8152.

48 N. Rubio, M. A. Herrero, A. de la Hoz, M. Meneghetti, M. Prato and E. Vázquez, Org. Biomol. Chem. 2010, 8, 1936.
49 V. S. Myers, M. G. Weir, E. V. Carino, D. F. Yancey, S. Pande and R. M. Crooks, Chem. Sci. 2011, 2, 1632.

50 M. A. Herrero, J. Guerra, V. S. Myers, M. V. Gomez, R. M. Crooks and M. Prato, ACS Nano 2010, 4, 905.

51 M. A. Dobrovolskaia and S. E. McNeil, Nat Nano 2007, 2, 469.

52 C. M. Wiethoff and C. R. Middaugh, J. Pharm. Sci. 2003, 92, 203.

53 V. C. Sanchez, A. Jachak, R. H. Hurt and A. B. Kane, Chem. Res. Toxicol. 2011, 25, 15.

54 C. A. Poland, R. Duffin, I. Kinloch, A. Maynard, W. A. H. Wallace, A. Seaton, V. Stone, S. Brown, W. MacNee and K. Donaldson, Nat Nano 2008, 3, 423.

55 T. Yamashita, K. Yamashita, H. Nabeshi, T. Yoshiwaka, Y. Yoshioka, S.-I. Tsunoda and Y. Tsutsumi, Materials 2013, 5, 350.

56 V. E. Kagan, Y. Y. Tyurina, V. A. Tyurin, N. V. Konduru, A. I. Potapovich, A. N. Osipov, E. R. Kisin, D. Schwegler-Berry, R. Mercer, V. Castranova and A. A. Shvedova, Toxicol Lett 2006, 165.

57 A. A. Shvedova, E. Kisin, A. R. Murray, V. J. Johnson, O. Gorelik, S. Arepalli, A. F. Hubbs, R. R. Mercer, P. Keohavong, N. Sussman, J. Jin, J. Yin, S. Stone, B. T. Chen, G. Deye, A. Maynard, V. Castranova, P. A. Baron, V. E. Kagan, Am. J. Physiol.-Lung C. 2008, 295, L552.

M. Uo, T. Akasaka, F. Watari, Y. Sato and K. Tohji, Dent. Mater. J. 2011, 30, 245 .

59 A. B. Kane and R. H. Hurt, Nat Nano 2008, 3, 378.

60 H. A. Dumortier, S. Lacotte, G. Pastorin, R. Marega, W. Wu, D. Bonifazi, J. P. Briand, M. Prato, S. Muller and A. Bianco, Nano Lett. 2006, 6, 1522.

61 C.P. Firme, P.R. B. Prabhakar Nanomedicine 2010, 6, 245.

62 S. Lacotte, A. García, M. Décossas, W. T. Al-Jamal, S. Li, K. Kostarelos, S. Muller, M. Prato, H. Dumortier, A. Bianco, Adv. Mater. 2008, 20, 2421.

63 H. Isobe, T. Tanaka, R. Maeda, E. Noiri, N. Solin, M. Yudasaka, S. Iijima and E. Nakamura, Angew. Chem. Int. Ed. 2006, 45, 6676.

64 Y. Tahara, M. Nakamura, M. Yang, M. Zhang, S. Iijima and M. Yudasaka, Biomaterials 2012, 33, 2762.

65 Y. Tahara, J. Miyawaki, M. Zhang, M. Yang, I. Waga, S. Iijima, H. Irie, M. Yudasaka, Nanotechnology 2011, 22, 265106. 
66

M. Zhang, X. Zhou, S. Iijima and M. Yudasaka, Small 2012, 8, 2524.

67 R. M. Lynch, B. H. Voy, D. F. Glass, S. M. Mahurin, B. Zhao, H. $\mathrm{Hu}$, A. M. Saxton, R. L. Donnell and M.-D. Cheng, Nanotoxicology 2007, 1, 157.

68 K. T. Al-Jamal, A. Nunes, L. Methven, H. Ali-Boucetta, S. Li, F. M. Toma, M. A. Herrero, W. T. Al-Jamal, H. M. M. Tena Eikelder, J. Foster, S. Mather, M. Prato, A. Bianco, K. Kostarelos, Angew. Chem. Int. Ed. 2012, 51, 6389.

69 B. L. Allen, G. P. Kotchey, Y. Chen, N. V. K. Yanamala, J. Klein-Seetharaman, V. E. Kagan and A. Star, J. Am. Chem. Soc. 2009, 131, 17194.

70 J. Russier, C. Menard-Moyon, E. Venturelli, E. Gravel, G. Marcolongo, M. Meneghetti, E. Doris and A. Bianco, Nanoscale 2011, 3, 893.

71 J. Kolosnjaj-Tabi, K. B. Hartman, S. Boudjemaa, J. S. Ananta, G. Morgant, H. Szwarc, L. J. Wilson and F. Moussa, ACS Nano 2010, 4, 1481.

72 H. Ali-Boucetta, A. Nunes, R. Sainz, M. A. Herrero, B. Tian, M. Prato, A. Bianco and K. Kostarelos, Angew. Chem. Int. Ed. 2013, 52, 2274.

73 E. Vázquez and M. Prato, ACS Nano 2009, 3, 3819.

74 M. A. Herrero and M. Prato, Mol. Cryst. Liq. Cryst. 2008, 483.

75 W. Huang, J. Zhang, H. C. Dorn, D. Geohegan and C. Zhang, Bioconjugate Chem. 2011, 22, 1012.

76 V. Biju, Chem. Soc. Rev. 2014, 43, 744.

77 G. Pagona, A. S. Sandanayaka, A. Maigné, J. Fan, G. C. Papavassiliou, I. D. Petsalakis, B. R. Steele, M. Yudasaka, S. Iijima, N. Tagmatarchis and O. Ito, Chem. Eur. J. 2007, 13, 7600 .

78 G. Pagona, G. Rotas, Petsalakis I.D., G. Theodorakopoulos, J. Fan, A. Maigne, M. Yudasaka, Iijima S. and N. Tagmatarchis, J. Nanosci. Nanotechnol. 2007, 7, 3468.

79 N. Tagmatarchis, A. Maigné, M. Yudasaka and S. Iijima, Small 2006, 2, 490.

80 C. Cioffi, S. Campidelli, F. G. Brunetti, M. Meneghetti and M. Prato, Chem. Commun. 2006, 2129.
81 F. G. Brunetti, M. A. Herrero, J. de Muñoz, A. Díaz-Ortiz, J. Alfonsi, M. Meneghetti, M. Prato and E. Vázquez, J. Am. Chem. Soc. 2008, 130, 8094.

82 F. G. Brunetti, M. A. Herrero, J. de Munoz, S. Giordani, A. DíazOrtiz, S. Filippone, G. Ruaro, M. Meneghetti, M. Prato and E. Vázquez, J. Am. Chem. Soc. 2007, 129.

83 N. Rubio, M. A. Herrero, M. Meneghetti, A. Díaz-Ortiz, M. Schiavon, M. Prato and E. Vázquez, J. Mater. Chem. 2009, 19, 4407 .

84 G. Pagona, N. Karousis and N. Tagmatarchis, Carbon 2008, 46, 604.

85 S. P. Economopoulos, G. Pagona, M. Yudasaka, S. Iijima and N. Tagmatarchis, J. Mater. Chem. 2009, 19, 7326.

86 N. Karousis, T. Ichihashi, M. Yudasaka, S. Iijima and N. Tagmatarchis, Chem. Commun. 2011, 47, 1604.

87 S. Matsumura, S. Sato, M. Yudasaka, A. Tomida, T. Tsuruo, S. Iijima and K. Shiba, Mol. Pharm. 2009, 6, 441.

88 J. Miyawaki, M. Yudasaka, H. Imai, H. Yorimitsu, H. Isobe, E. Nakamura and S. Iijima, Adv. Mater. 2006, 18, 1010.

89 E. Miyako, H. Nagata, K. Hirano, Y. Makita, K.-i. Nakayama and T. Hirotsu, Nanotechnology 2007, 18, 475103.

90 S. Sarkar, A. A. Gurjarpadhye, C. G. Rylander and Rylander M.N., J Biomed Opt. 2011, 16, 051304.

91 M. Zhang, T. Murakami, K. Ajima, K. Tsuchida, A. S. D. Sandanayaka, O. Ito, S. Iijima and M. Yudasaka, Proc. Natl. Acad. Sci. 2008, 105, 14773.

92 E. Miyako, H. Nagata, K. Hirano, K. Sakamoto, Y. Makita, K.-i. Nakayama and T. Hirotsu, Nanotechnology 2008, 19, 075106 .

93 Hagihara, M. Horie, M. Shichiri, Y. Higuchi, F. Yamashita, M. Hashida, Y. Shigeri, Y. Yoshida and S. Iijima, Proc. Natl. Acad. Sci. 2012, 109, 7523

94 W. Huang, J. Zhang, H. C. Dorn and C. Zhang, PLoS ONE 2013, 8 , e74679. 


\section{Table of Contents Entry.}

Carbon nanohorns serve as carriers for genetic material and chemotherapeutics that permits the incorporation of targeting ligands and minimal toxicity.

Keyword (carbon nanohorns, nanotubes, gene delivery, siRNA, PAMAM dendrimers)

\section{J. Guerra, M.A. Herrero, E. Vázquez*}

ToC figure.

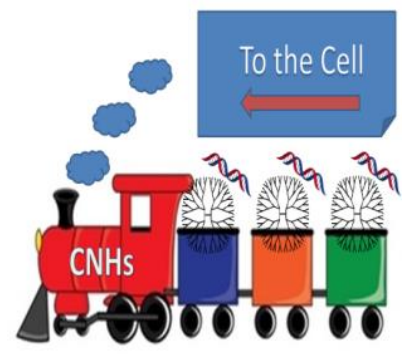

\section{Biographical Sketches}

Javier Guerra obtained his PhD (2006) at University of Castilla-La Mancha (UCLM). Dr Guerra spent two years as postdoctoral fellow at the University of Texas at Austin with Prof. Richard M. Crooks. After a period working at UCLM, CIBERNED and NanoDrugs SL, he currently works as R\&D technician at Crystal Pharma SAU. He has authored 24 manuscripts, with 4 patents under evaluation. He has been awarded with the National Suschem-INNOVA prize as young researcher.

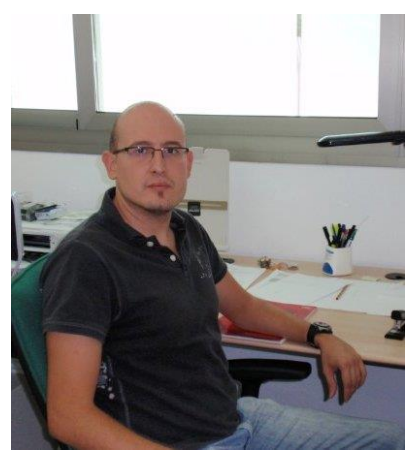

In 2006, Dr. M. Antonia Herrero obtained the European PhD degree, UCLM. She started her formation on nanoscience with Prof. M. Prato. Afterwards, she joined the MSOC-nanochemistry group in the UCLM. She has authored over 35 scientific publications, some book chapters and four scientific patents. In 2010 she received the award "women for science" by L'OrealUNESCO and in 2011 "Ibn Wafid de Toledo". She was selected as "Ramon y Cajal" in 2010. She was promoted to Associate Professor in 2011, UCLM. In 2012, Iberdrola Fundation granted a project for the integration of carbon nanomaterials in solar cells.

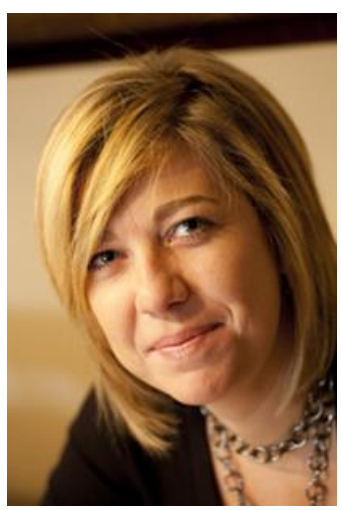

Ester Vázquez obtained her Ph.D. from the University of Castilla-la Mancha (UCLM) in 2000. She carried out her postdoctoral training in 25 Trieste, working with Professor Maurizio Prato, in the frame of a European Research Training Network. She joined the Faculty of Chemistry at UCLM in 2001, being promoted to Associate Professor in 2010. In 2009, she received the "Ibn Wafid de Toledo" Price for young researchers of Castilla- La Mancha. Her group has used microwave 30 radiation and ball-milling methodologies for the activation of carbon nanostructures, preparing multifunctional derivatives that can serve as versatile synthons in materials science and biological applications. 


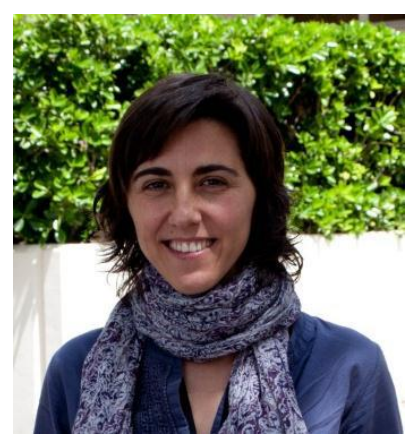

